\title{
Protection from Direct Lightning Strike in the Main Building of the Polytechnic University of Tirana
}

\author{
Xhemali Pejtamalli 1 \\ Piro Cipo \\ Aldi Muçka ${ }^{3}$ \\ Fatmir Vrapi ${ }^{4}$

\begin{abstract}
${ }^{1}$ Electrotechnical Department - Electrical Engineering Faculty, Polytechnic University of Tirana ${ }^{2}$ Electrotechnical Department - Electrical Engineering Faculty, Polytechnic University of Tirana ${ }^{3}$ Electrical Power System Department- Electrical Engineering Faculty, Polytechnic University of Tirana ${ }^{4}$ Faculty of Mathematics and Physics Engineering, CFL, Polytechnic University of Tirana
\end{abstract}

Doi:10.5901/ajis.2015.v4n2s2p250

\section{Abstract}

This paper presents a model of analyzing the transient process of dissemination of electromagnetic wave of the lightning protection system, which is placed on the terraces of the Polytechnic University of Tirana. According to this study simulations were conducted by using the well-known ATP-EMTP software. We have calculated the values of voltages and currents and have also analyzed them. The modeling of conducting segments of protective grid is made by line losses with distributed parameters according to Clark's model. Direct lightning strike to the protection network, is modeled with the Heidler's type of current source. Analytical expressions for distributed and lumped segment parameters derive from use of the average potential method. The number of the segments required for an accurate simulation depends on the highest frequency of the injected impulse. This paper presents a transmission line model (TLM). Direct lightning strike onto the top of the building of the Polytechnic University of Tirana is considered. By comparing the results obtained by TLM model and those developed by a more exact electromagnetic model, a specific similarity has been observed, both in the computed amplitude of the overvoltage, as well as in the temporal and spatial overvoltage distribution. Due to the limitations of the transmission line model approach and the application of the ATP-EMTP software package, the electromagnetic coupling between segments is not be taken into account. The earth model is limited to the heterogeneous earth. The soil ionization effect can be included.

Keywords: Simulation, transient process, lines with distributed parameters, direct lightning strike, overvoltage, over current.

\section{Introduction}

Lightning can be defined as a temporary high discharge to earth, which occurs when certain regions of the atmosphere reach a sufficiently large electric charge in connection with the earth. From this phenomenon arises a great power that affects the sensitive electrical and electronic systems and causes malfunction or destruction. From the lightning strike, electrical power is the most important form of the lightning discharge. Electrical problems of protection against lightning can be treated and solved by knowing the form of wave and current amplitude. Efficiency of protection from undesirable lightning phenomena is closely related to proper design of protective systems.

The main purpose of any protection system from direct lightning strike is to discharge within a shorter time on earth, the current caused by the lightening. During this time, buildings and people can be damaged, including electric and electronic systems. Research work has been performed for the Earthing systems, both theoretically and experimentally. The theoretical treatment is based on analytical methods, mostly empirical and numerical methods [1].

In our country, there is no thorough study and calculation of lightning protection systems. Protection against lightning direct strike, by IEC-62305 standard, represents a significant problem of protection. The study conducted by the authors is based on this standard and is simulated by means of the package Software ATP (Transient Alternative Program). For simulation model is used Clark officials, where the segments are replaced with line losses, with distributed parameters. Setting of lightning rod is controlled by means of the method of protective angles and rotating spheres. 


\section{Contents}

\subsection{The calculation of the parameters $R, L, C$ protection systems from direct stroke.}

Every protection system, from direct lightning strokes, consists of wires that have a particular placement in space. In the special case, it consists of wires of vertical and horizontal position. In view of the position, the capacity is further calculated owing to its function and inductivity of the conductor is calculated.

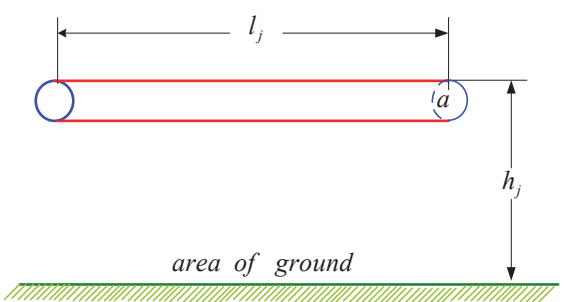

Fig. 1: A circular wire with a length ${ }^{l_{j}}$ height from the ground ${ }^{h_{j}}$ and radius $a$

By [4] for conductor with horizontal position, figure 1 its capacity is calculated:

$$
\begin{aligned}
& C_{j}=\frac{2 \cdot \pi \cdot \varepsilon_{0} \cdot l_{j}}{\ln \left(\frac{2 h_{j}}{a}\right)-D_{1}}[\mathrm{~F}] \\
& \left.D_{1}=\ln \left(1+\sqrt{1+\frac{\left(4 h_{j}\right)^{2}}{\left(l_{j}\right)^{2}}}\right)+\left(\frac{2 h_{j}}{l_{j}}\right)-\sqrt{1+\frac{\left(4 h_{j}\right)^{2}}{\left(l_{j}\right)^{2}}}\right)+0.307
\end{aligned}
$$

and the conductor having vertical position, as in figure 2, its capacity is calculated:

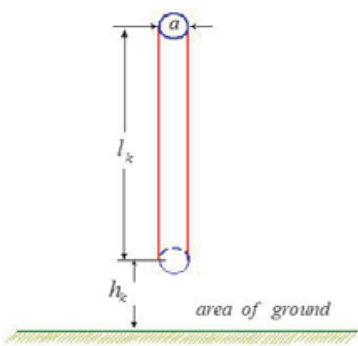

Fig. 2: A conductor length ${ }^{l_{k}}$ height from the ground ${ }^{h_{k}}$ and radius $a$

To calculate the capacity of vertical segments, let's look at the following cases:

The first case : the ratio $\frac{h_{k}}{l_{k}}<1$ then constant $D_{2}$ It has the form:

$D_{2}=1+\frac{h_{k}}{l_{k}} \ln \left(\frac{4 h_{k}}{l_{k}}\right)+\left(1+\frac{h_{k}}{l_{k}}\right) \ln \left(1-\frac{h_{k}}{l_{k}}\right)-\left(1+\frac{2 h_{k}}{l_{k}}\right) \ln \left(1+\frac{2 h_{k}}{l_{k}}\right)$

Second case: the ratio $\frac{h_{k}}{l_{k}}>1$ then constant $D_{2}$ It has the form:

$$
D_{2}=0.307+\left(1+\frac{h_{k}}{l_{k}}\right) \ln \left(1+\frac{l_{k}}{h_{k}}\right)-\left(1+\frac{2 h_{k}}{l_{k}}\right) \ln \left(1+\frac{l_{k}}{2 h_{k}}\right)
$$


2.2 Separation of conductor of protective system, in particular segments of length that are part of the electromagnetic wavelength that spreads into the surrounding environment and the calculation of the maximum frequency of the lightning power source

Every function related to time, can be transformed in the frequency area, through the Furie integral transformation. Considering as final the spectrum of frequencies, thus ignoring the very high frequencies, maximum frequency, for practical purposes, it is calculated based on the time of the wave front $\tau_{f}$ :

$$
f_{\max } \approx \frac{1}{\tau_{f}}
$$

In function of the maximum frequency, it is possible to determine, the minimum length of the electromagnetic wave. Hence, in function of the length of the electromagnetic wave $\lambda_{\min }$, is calculated the length of the segment $\Delta L$ which will be represented by the equivalent electric circuit. As a criterion for calculating the length of the segment the following formula is used (7):

$$
\Delta L<\frac{\lambda_{\min }}{10}
$$

In outdoor environments, therefore, the external systems of protection from direct lightning stroke, dielectric and magnetic constants of emptiness are:

$$
\begin{aligned}
& \mathcal{E}=\varepsilon_{o} ; \mu=\mu_{0} \\
& \lambda_{\min }=\frac{c}{f_{\text {max }}} \\
& \lambda_{\min }=\frac{300}{f_{\max }[M H z]}[\mathrm{m}]
\end{aligned}
$$

So, in the external systems of protection from lightning stroke the length of the segment is calculated by the formula (11):

$$
\Delta L<\frac{30}{f_{\max }[M H z]} \quad[\mathrm{m}]
$$

\subsection{The calculation parameters steep circular conductors}

Calculation of capacity, figure 3 , is performed using the following formula:

$$
C=\frac{4 \pi \varepsilon \cdot \Delta L}{\iint_{\Gamma} \frac{\Delta L \cdot \Delta L^{\prime}}{r}-\iint_{\Gamma_{S} \Gamma} \frac{\Delta L_{S} \cdot \Delta L}{r}}=\frac{4 \pi \varepsilon \cdot \Delta L}{I_{\text {iself }}-I_{\text {coupled }}}
$$

where, counting double integrals in formula (12) based on figure 3, we obtain the formula (13)

$$
I_{\text {istelf }}=2 \cdot\left[\Delta L \cdot \ln \left(\frac{\sqrt{(\Delta L)^{2}+\left(r_{0}\right)^{2}}+\Delta L}{r_{0}}\right)-\sqrt{(\Delta L)^{2}+\left(r_{0}\right)^{2}}+r_{0}\right]
$$

where: $r_{0}$ - It is the radius of the conductor.

The double integrating in one of the integrals of formula (12) is made in the axis of the segment (premium gamma curve in Figure 3) and according to the curve on the surface of the segment which is parallel to its axis

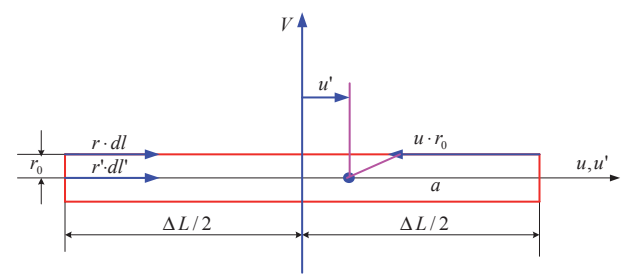

Fig. 3. Integration mode according to the axis and under surface of the conductor segment with the lengths shown in the picture 
The second integral in formula (12), the segment (conductor) is steep, Figure 4, calculated:

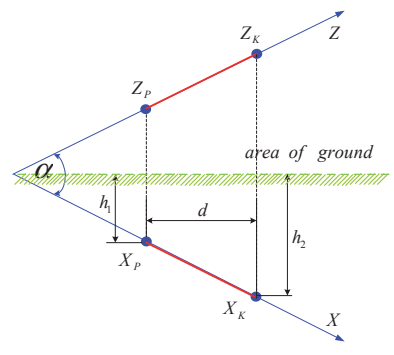

Fig 4. Segment steep, beginning and end coordinates, angle of slope

We calculate the length of the conductor:

$$
\Delta L=\sqrt{d^{2}+\left(h_{2}-h_{1}\right)^{2}}
$$

The coordinates are calculated:

$$
\begin{aligned}
& X_{P}=Z_{P}=\frac{\min \left\{h_{1}, h_{2}\right\}}{\left[h_{2}-h_{1}\right]} \cdot \Delta L \\
& X_{k}=Z_{k}=\frac{\max \left\{h_{1}, h_{2}\right\}}{\left[h_{2}-h_{1}\right]} \cdot \Delta L \\
& \cos (\alpha)=\frac{2 \cdot g^{2}}{(\Delta L)^{2}}-1
\end{aligned}
$$

The second integral above formula (12), has the form:

$$
I_{\text {coupled }}=2 \cdot\left[B\left(X_{P}, Z_{P}\right)+B\left(X_{K}, Z_{K}\right)-B\left(X_{P}, Z_{K}\right)-B\left(X_{K}, Z_{P}\right)\right]
$$

where the function $\mathrm{B}(\mathrm{X}, \mathrm{Z})$, provided that the radius of the segment to be: $r_{0} \ll \Delta L$ is calculated in the form:

$$
B(X, Z)=X \cdot \ln \left(Z-X \cdot \cos \alpha+\sqrt{X^{2}+Z^{2}+r_{0}^{2}-2 \cdot X \cdot Z \cdot \cos \alpha}\right)
$$

\subsection{Protection of the main building of the PUT, direct stroke lightning}

In figure 5, it is presented the protection with lightning rods at the height $5 \mathrm{~m}$, in the main building PUT

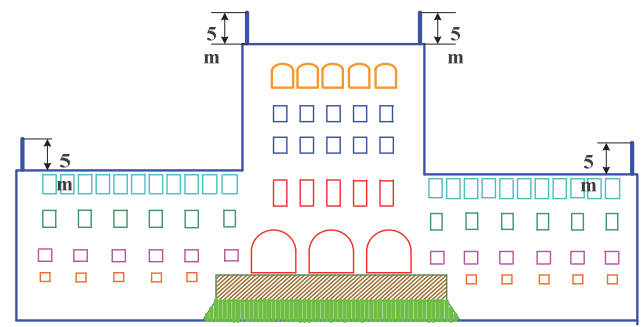

Fig 5. Protection with lightning rods at the height of $5 \mathrm{~m}$, in the main building terraces of PUT

Relying on international standards: IEC-62305, protection angles have been found, referring to different plans, shown in Figure 6. 


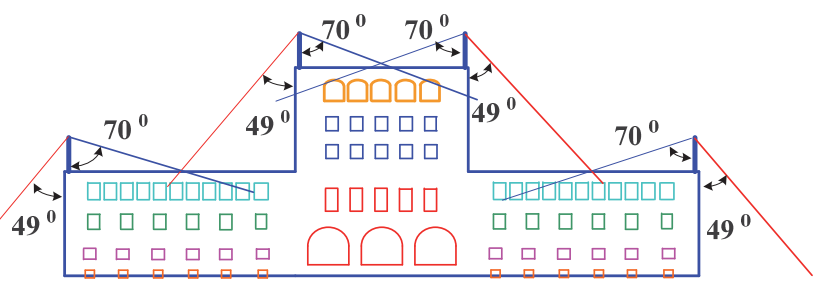

Fig 6. Determination of protective angles versus the reference plans as defined with the help of protection level III

Figure 7 shows the areas of coverage of lightning strikes. It is seen that there are three spots which are not completely covered.

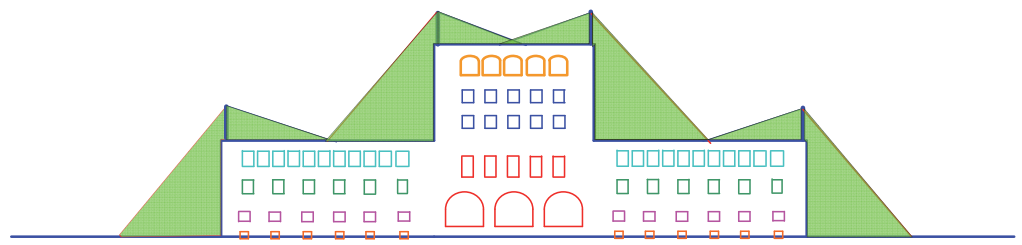

Fig 7. Areas covered by the lightning strike protection under the angles in Figure 6

In Figure 8 is shown the appearance from above of the terraces of the PUT main building by clearly showing the coverage areas by lightning conductor located on the terraces of the main building according to plan, as presented in Figure 9. From these figures, it is obvious that there are some doubtful spots that do not ensure good coverage of these areas from direct lightning strike. To ensure full coverage and to increase the security of protecting these areas from lightning strikes, three lightning rods have been added, in the spots which are clearly noticed in the layout shown in Figure 10

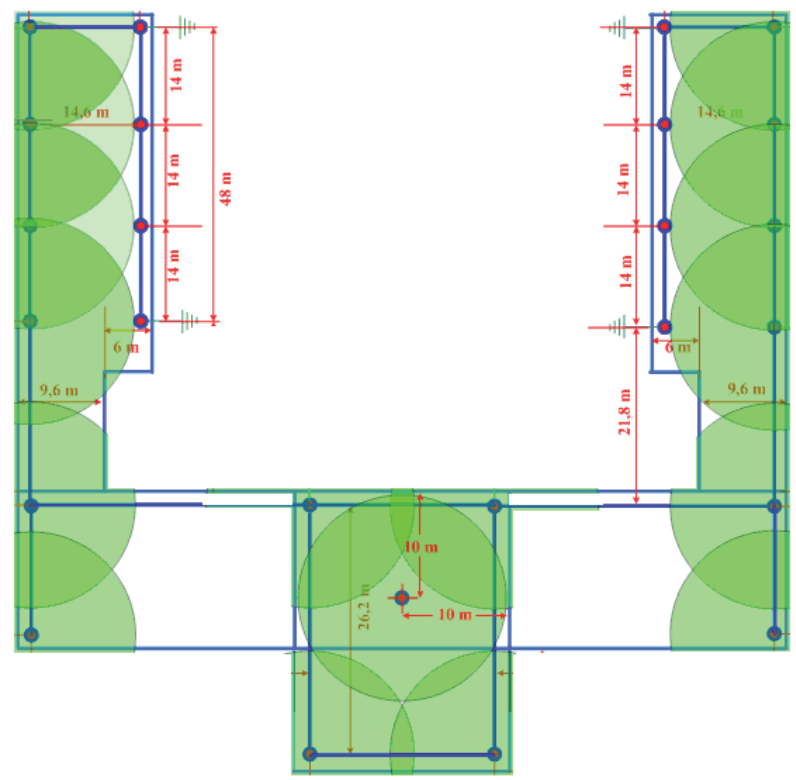

Fig. 8. Views from the top of catchment areas by lightning conductor length $5 \mathrm{~m}$ 


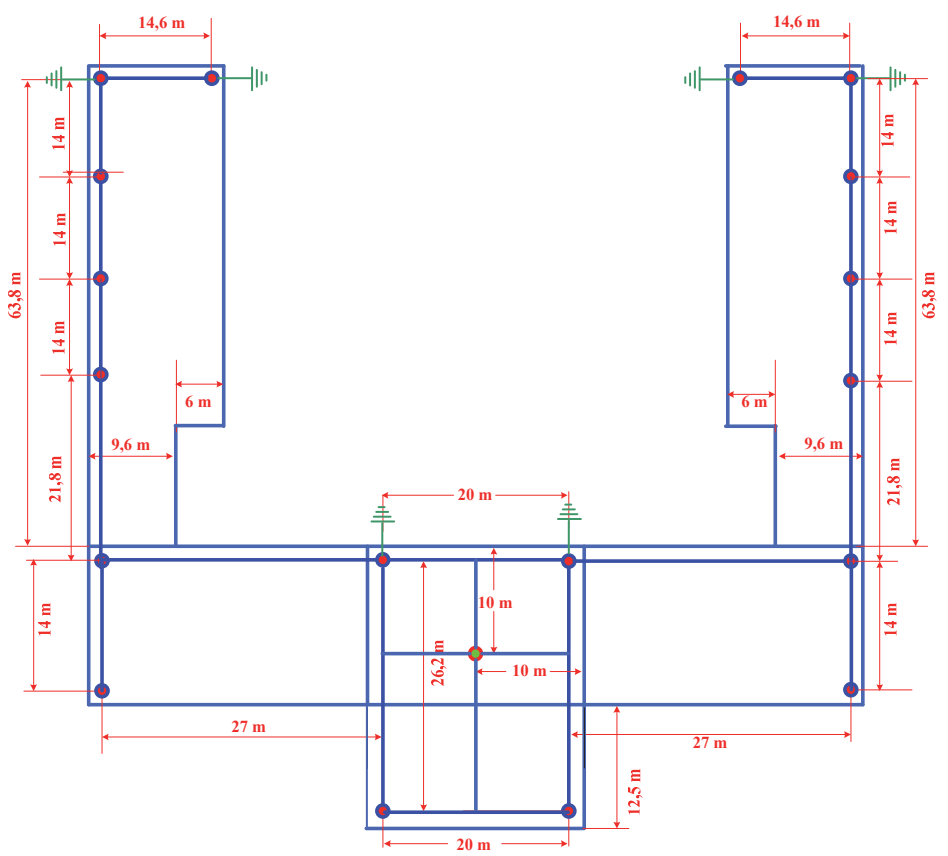

Fig. 9. layout of placing the lightning rods with $5 \mathrm{~m}$ length on the terraces of PUT

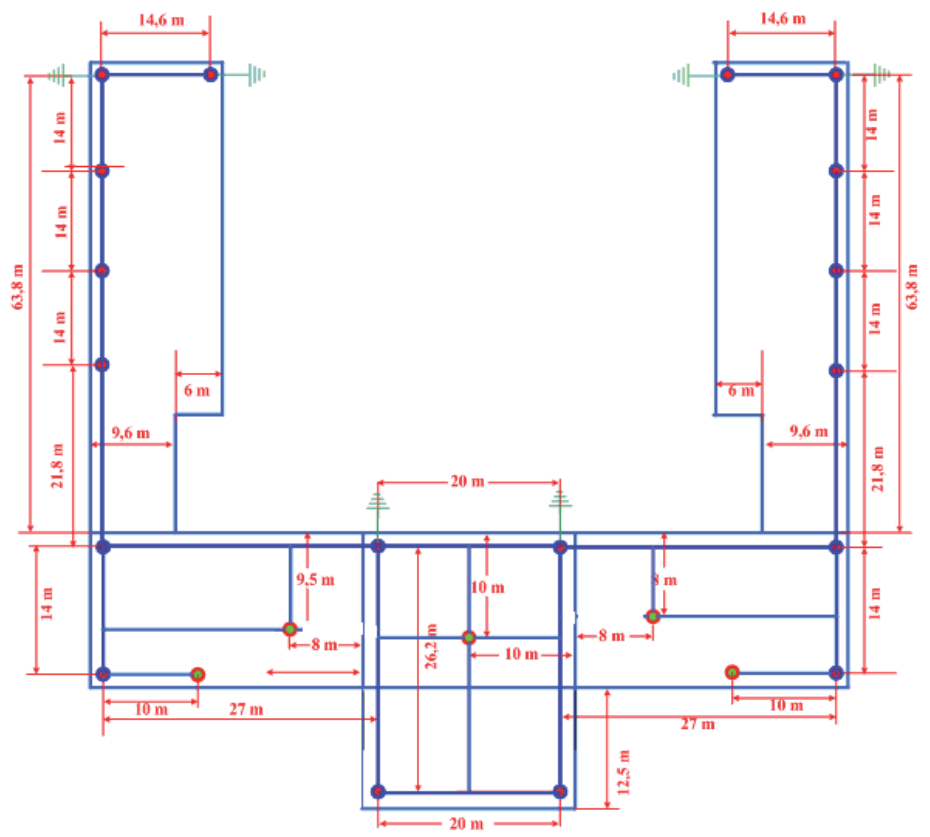

Fig. 10. The plan of placing the additional lightning rods on the terraces of the PUT 


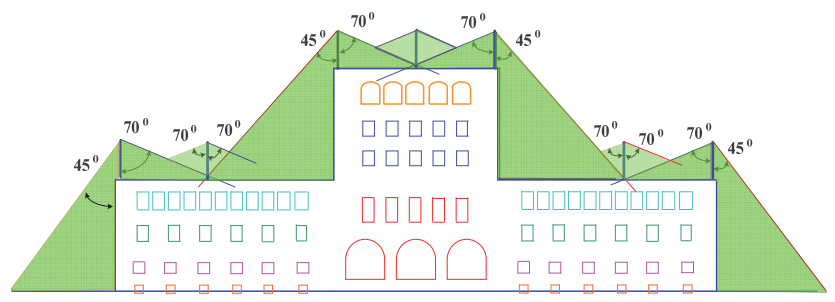

Fig. 11. Areas covered by the lightning strike, according to protection angles after placing additional lightning rods.

In figure 12 is presented the view from the terraces above the main building of the Polytechnic University, as we added three additional lightning rods. As clearly seen in Figure 12, it becomes a full coverage protection from direct lightning strikes of all terraces in the Polytechnic Building.

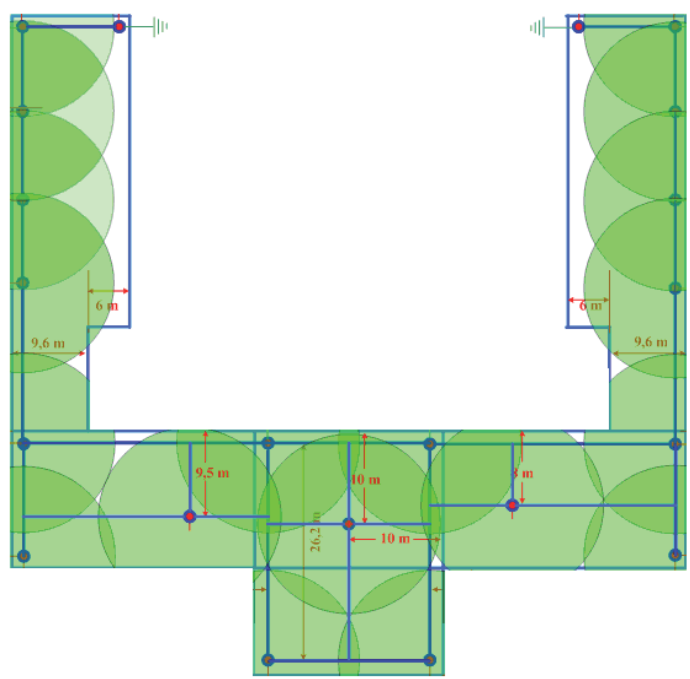

Figure 12. View from above of catchment areas by lightning rod with a length $5 \mathrm{~m}$, after placing the additional lightning rods.

In figure 12, it seems that the coverage is satisfactory, for the protection from the lightning strike. The authors have also used the method of rotating spheres, taking the radius of the sphere $R=45[\mathrm{~m}]$, based on level III protection .

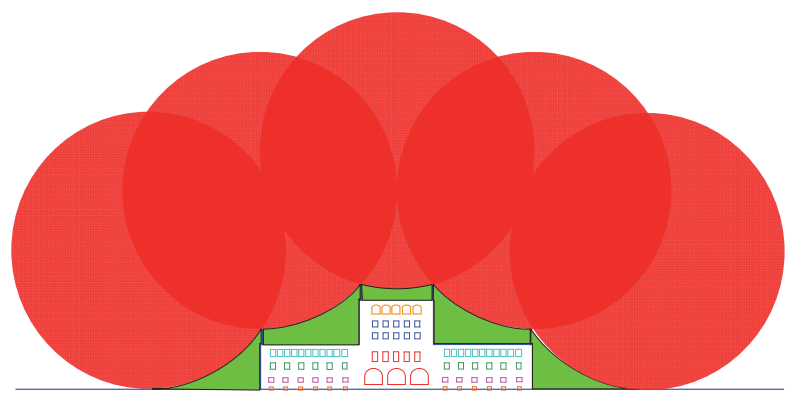

Fig 13. View full coverage using the method of rotating spheres. Green color shows areas covered by the lightning conductor. 
In Figure 14, we present ATP simulation model of lightning rods network.

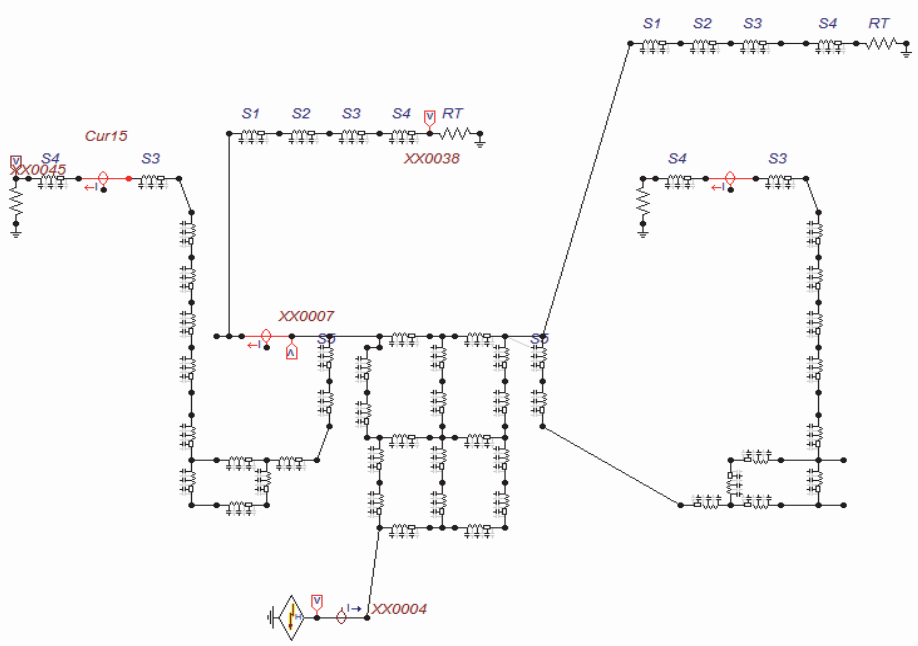

Fig. 14. the ATP model of the protective network on PUT terraces

From analysis in Figure 15, are given the current wave of lightning Standard Users: 1.2 / 50 [ $\mu \mathrm{s}]$ crested 10 [KA] and waves of currents in the descending wires.

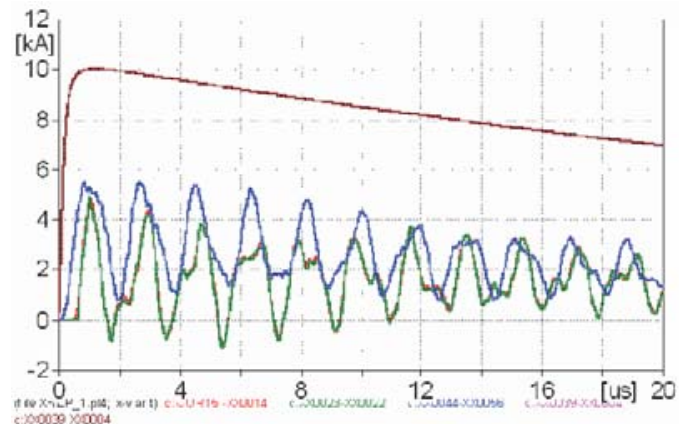

Fig. 15. lightning main current 1.2 / $50 \mu$ s and currents in descending branches $15 \mathrm{~m}$ and $30 \mathrm{~m}$.

In Figure 16, is given the law of change of voltage node, where the relevant wave lightning strikes,

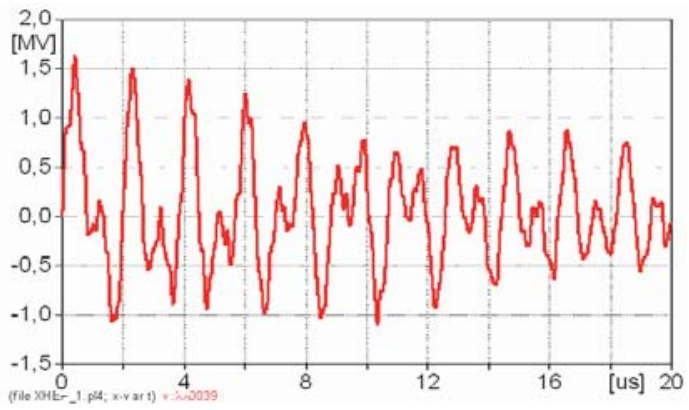

Fig. 16. the law of voltage change in the node of lightning striking 1.2 / $50 \mu \mathrm{s} 10$ [AC]. 
From the analysis performed, we present the law of voltage change on the descending conductor with a length of $15[\mathrm{~m}]$, from the roof to the ground, to the point where it joins the Earthing resistance, Rt $=15[\Omega]$

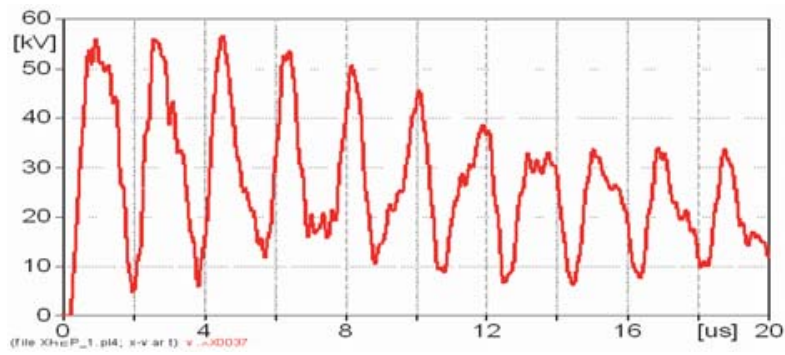

Figure 17. Voltage in node where it joins earth resistance

\section{Conclusions}

In this study, the authors have realized the protection of the main building of Polytechnic University of Tirana, using the method of protection angels as well as the method of rotating spheres. From the analysis, it turned out that adding three lightning rods, the requirements of protection from direct lightning stroke are met.

As a result of the shock wave lightning standard: $1.2 / 50[\mu \mathrm{s}]$, crested $10[\mathrm{kA}]$, over voltages and large over currents occur which by placing earth resistance with small resistance grounding to $2[\Omega]$, we have the opportunity to minimize over voltages at various points of the network protection as provided by the authors.

\section{References}

P.Sarajcev and R.gojic, "A review of current issues in state of art of wind farm overvoltages protection, "Energies, vol. 4, no. 4.

C.R.Paul, Inductance-loop and Partial, John Wiley\&Sohns, New Y, NY,USA, 2010.

P.I.Kalantarov and Ceitlin, Inductance Calculation,Energy press, 1992.

U.V.Iosseli, A.S. Kothanov and M.G.Stlyrski,Capacitance Calculation, Energy Press, 1990.

Slavko Vujević, Petar Sarajčev and Jakov Petrović, "TLM model for the lightning Transient Analysis of the GSM Base Station, Workshop"Impact of Communication Technology to EMC"

De Conti, A., S. Visacro, A. Soares, and M. A. O. Schroeder,IRevision, extension, and validation of Jordan's formula to calculate the surge impedance of vertical conductors," IEEE Transactions on Electromagnetic Compatibility, Vol. 48, 530 536,2006.

Gao, C., L. Li, B. Li, and Z. Zhao, IComputation of power line tower lightning surge impedance using the electromagnetic ${ }^{-}$eld method," Proceeding IEEE, EMC-Zurich, 124\{127, 2006.

Gutierrez, J. A., et al., INonuniform transmission tower model for lightning transient studies," IEEE Transactions on PowerDelivery, Vol. 19, 490\{496, 2004.

Ametani, A., Y. Kasai, J. Sawada, A. Mochizuki, and T. Yamada, IFrequency-dependent impedance of vertical conductors and a multiconductor tower model," IEE Proceeding Generation, Transmission and Distribution, Vol. 141, 339\{345, 1994.

Rogers, E. J. and J. F. White, IMutual coupling between ${ }^{-}$nite lengths of parallel or angled horizontal earth return conductors,"IEEE Transactions on Power Delivery, Vol. 4, 103\{113, 1989.

Rudenberg, R., Electrical Shock Waves in Power System, Harvard Univ. Press, Cambridge, MA, 1968.

Dwight, H. B., ICalculation of the resistances to ground," Elec.Eng., Vol. 55, 1319\{1328, 1936.

Sunde, E. D., Earth Conduction E®ects in Transmission Systems,2nd Edition, Dover, New York, 1968.

Kaouche, S., S. Mezoued, B. Nekhoul, K. Kerroum, and K. El Khamlichi Drissi, Unduced disturbance in power network by lightning," Proceeding IEEE EMC Europe, 935\{940, 2006.

Paul, C. R., Analysis of Multiconductor Transmission Lines, 2nd Edition, Wiley-IEEE Press, 2007.

Visacro, S., A. Soares, Jr., M. A. O. Schroeder, L. C. L. Cherchiglia, and V. J. Souza, IStatistical analysis of lightning current parameters: Measurements at Morro 